\title{
DA MULTIPLICIDADE, DO MULTILETRAMENTO À CONSTRUÇÃO DO SENTIDO: GÊNEROS MULTIMODAIS E PRÁTICAS DISCURSIVAS
}

\author{
FROM THE MULTIPLICITY, FROM THE MULTILITERACY TO THE CONSTRUCTION OF \\ THE MEANING: MULTIMODAL GENRES AND DISCURSIVE PRACTICES
}

\section{Cristiano Oldoni' ${ }^{1}$ Ernani Cesar de Freitas²}

Recebido em: 10 de maio de 2017

Aprovado em: 30 de junho de 2017

Sistema de Avaliação: Double Blind Review

RPR | a. 14 | v.2 | p. 16-28 | jul./dez. 2017

\section{RESUMO}

A comunicação e a linguagem contemporâneas têm suscitado produtivas reflexões acerca de suas reconfigurações, especialmente em situações em que se vinculam com as noções de gênero e multimodalidade. As vivências discursivas exigem que os envolvidos na dinâmica comunicativa convertam-se em efetivos sujeitos que, por meio das textualidades multissemióticas, estabelecem novas formas de interação e colaboração. Nesse movimento, ao passo em que surge uma nova leitura, marcada pela multiplicidade e por novas tecnologias, surgem também um novo leitor e uma nova necessidade, o hiperletramento. Com esse panorama, o presente estudo propõe como objetivo não somente rediscutir os conceitos apresentados, mas refletir sobre suas associações na tentativa de compreender as inéditas realidades discursivas e as contemporâneas práticas de linguagem. Baseando-se em especial nas contribuições de Bakhtin (2011), Petit (2008), Cope e Kalantzis (2000) e Rojo (2012), o presente artigo apresenta pesquisa qualitativa com abordagem bibliográfica na análise de corpus representado por um videoclipe de abertura de série de entretenimento e aponta para a importante colaboração das multiplicidades no resgate de sentidos projetados pelos gêneros multimodais.

Palavras-chave: Gêneros textuais-discursivos. Leitura; Multimodalidade. Multiletramentos.

\section{ABSTRACT}

The contemporary communication and language have produced relevant reflections on their reconfigurations, especially in situations where they are linked to genre and multimodality notions. Discursive experiences require from the people involved that they become effective subjects in the communicative dynamic. So, through multisemiotic textualities they establish the latest ways of interaction and collaboration. Thus, as a new reading emerges and it is characterized by the multiplicity and recent technologies, hyperliteracy appears full of necessities. The present study proposes not only rediscuss the concepts presented, but also reflect about their associations. It is important to highlight that this study attempts to understand the unprecedented discursive realities and the contemporary practices of the language. This article presents a qualitative research with a bibliographical approach in the analysis of the corpus which is based on the contributions of Bakhtin (2011), Petit (2008), Cope and Kalantzis (2000) and Rojo (2012). The corpus is represented by an opening video from an entertainment series. Furthermore, this video points to the important collaboration of the multiplicities for the rescue of the senses projected by the multimodal genres.

Keywords: Textual-discursive genres. Reading. Multimodality. Multiliteracy.

\footnotetext{
${ }^{1}$ Doutorando em Letras (Leitura e Formação do Leitor) pela Universidade de Passo Fundo (Passo Fundo/Brasil). E-mail: cristianooldoni@gmail.com.

${ }^{2}$ Doutor em Letras pela Pontifícia Universidade Católica do Rio Grande do Sul (Porto Alegre/Brasil), com pós-doutorado em Linguística Aplicada e Estudos da Linguagem pela Pontifícia Universidade Católica de São Paulo (São Paulo/Brasil). Professor na Universidade de Passo Fundo (Passo Fundo/Brasil). E-mail: ecesar@upf.br.
} 


\section{CONSIDERAÇÕES INICIAIS}

Se há algum tempo a construção de sentidos das mais variadas produções discursivas esteve atrelada à linearidade de suas manifestações, resultado da predominância de plataformas analógicas, a comunicação contemporânea, seja ela no domínio do jornalismo, da literatura, da música, da arte de rua, das artes plásticas, entre infinitos outros, somente pode ser semantizada a partir de uma concepção voltada à multiplicidade.

A estética dessas manifestações discursivas, cuja relação com variados planos de sentido é absolutamente íntima, converte-se, não por acaso, em uma das bases de questões e construções sociais da contemporaneidade. Na mescla do presencial e do virtual, da onipresença e da ausência (raramente consentida), vive-se do encontro com a multiplicidade de temas, focos, recortes, signos, plataformas e centros.

Princípio constante da contemporaneidade, a multiplicidade mostra-se, talvez por ser marca de uma nova comunicação, em elementos como autorreferência, abundância de fontes nas construções discursivas e alteridade de centros referenciais. Nesse cenário, a construção de sentidos ultrapassa uma percepção estética e vincula-se intimamente com uma ideia global de multiplicidade ${ }^{3}$ que valoriza e enobrece fragmentos da realidade postos lado a lado em inéditas e incessantes construções perceptíveis a cada nova interação, a cada nova leitura.

É considerando essa perspectiva que, no presente artigo, propomos a retomada e a breve discussão de conceitos interessantes à contemporaneidade, como leitura, gêneros discursivos, multimodalidade e multiletramentos. A partir da reflexão empreendida, objetivamos perceber quais são os pressupostos de uma efetiva leitura que envolva o domínio de habilidades específicas para interação e integração de semioses múltiplas, fomentadoras da comunicação na era da multiplicidade e possibilitadoras de encontros significativos com a própria realidade por meio do ato de ler.

O estudo aqui apresentado envolve pesquisa qualitativa com abordagem bibliográfica na análise de corpus representado por um videoclipe de abertura de série de entretenimento e aponta para a importante colaboração das multiplicidades no resgate de sentidos projetados pelos gêneros multimodais. Por isso, são base de nossa discussão as contribuições de Bakhtin (2011) acerca de gêneros discursivos, de Cope e Kalantzis (2000) sobre multimodalidade, de Petit (2008), em alusão à prática de leitura, e Rojo (2012) ao nos referirmos aos multiletramentos.

Para dar forma à nossa proposta, apresentamos nossas reflexões em três seções: na primeira delas discutimos uma concepção para a leitura a partir do comportamento humano e das relação construídas com a realidade; na segunda seção, abordamos a dinâmica de construção de sentidos por meio dos gêneros discursivos e da multimodalidade; a partir dessas considerações, na terceira seção, dedicamonos à análise de corpus representado por um videoclipe de abertura de série de comédia dramática, com base nos elementos teóricos especificados nas primeiras seções.

\section{A PROPÓSITO DOS ENCONTROS}

Tão relevante quanto a percepção da manifestação das extremamente variadas atividades humanas por meio de gêneros textuais-discursivos é a capacidade de interação com e por meio deles. Entrar em contato e promover a interação são tarefas que acontecem com a mediação da leitura que,

\footnotetext{
${ }^{3}$ Nossa referência à noção de "multiplicidade", neste estudo, está ancorado nas reflexões propostas pelo New London Group (2000) e por Rojo (2012): ainda que tal conceito não tenha sido proposto de forma direta, as alusões à multiculturalidade e às multissemioses permitem-nos o emprego da terminologia, uma vez que ambas - assim como as multiplataformas - têm sua carga basilar na matriz da multiplicidade. Exploramos esse conceito com maior profundidade na seção 2.1 deste artigo.
} 
nesse sentido, adquire status prévio de dispositivo de construção de sentidos, possibilitando a mobilidade e a circulação entre possíveis lógicas, entendimentos e direções de interpretação projetadas com a própria leitura, construída a partir das condições, vivências e experiências do leitor. Alcançado o propósito de produção de sentido, a leitura representa a possibilidade de estabelecer entre o leitor e o mundo uma íntima relação, especialmente em tempos em que todos buscam a construção de identidades próprias, experimentando novas referências com a transposição de supostos limites, em especial ao assumir os riscos que a atitude leitora pressupõe.

A leitura deve adquirir um patamar que ultrapasse a técnica e a tecnologia da decifração para que possa ampliar significados e promover novos saberes: as bruscas e rápidas mudanças sociais da contemporaneidade podem, por um lado, dar a impressão da perda de controle, de impotência diante do desconhecido, e, por outro, a leitura representa a preparação do indivíduo para possíveis demandas e processos que o marginalizariam em uma sociedade de preconceitos velados. É assim que a leitura pode converter-se em um verdadeiro mensageiro para a produção de sentidos. Se em tempos passados a leitura não alcançava status de processo de libertação (visto que eram instrumentos de dominação política, social e religiosa), atualmente vivemos uma realidade diferente, em um mundo de permanentes evoluções e transformações, no qual o futuro torna-se uma prospecção quase que intangível. Nesse panorama, a leitura de imersão, crítica e autônoma, adquire seu fundamental papel de construção do sujeito integrado ao seu meio.

Graças às plataformas virtuais e ao texto conectado em rede, a leitura tem se firmado como grande aliada do entendimento das dinâmicas interpessoais, como arauto de novas e múltiplas realidades, como nexo das próprias representações simbólicas de interação social. Michèle Petit (2008, p. 19, grifo nosso) observa que

[...] se a proporção de leitores assíduos diminuiu, a juventude continua sendo [...] o período da vida em que a atividade de leitura é mais intensa. E para além das grandes pesquisas estatísticas, ao escutarmos esses jovens falarem, compreendemos que a leitura de livros tem para eles algumas vantagens específicas que a distingue de outras formas de lazer. Compreendemos que por meio da leitura, mesmo esporádica, podem estar mais preparados para resistir aos processos de marginalização. Compreendemos que ela os ajuda a se construir, a imaginar outras possibilidades, a sonhar. A encontrar um sentido. A encontrar mobilidade no tabuleiro social. A encontrar a distância que dá sentido ao humor. E a pensar, nesses tempos em que o pensamento se faz raro.

Além de dispositivo de projeção/produção de sentidos, o ato de ler é provocação à reflexão social, é possibilidade de encontrar sentidos para a própria vida e representa um indispensável encorajamento ao pensar. Assim, conquista espaço cada vez mais diferenciado uma leitura cunhada pelo espírito da coletividade e da conectividade realizáveis no hipertexto que, com construções infinitas, possibilita que $\mathrm{o}$ ato de ler torne-se, simbolicamente, também infindável. A partir disso, reafirma-se a inflexível liberdade do leitor, agente por natureza, que, ao ler, reescreve o escrito, altera e reconstrói sentidos, reposiciona peças da construção uma realidade firmada na multiplicidade. O encontro com o mundo por meio da leitura é, com toda ênfase, possibilidade da interação que promove a autoconstrução no resgate de sentidos construídos colaborativamente.

Nessa perspectiva, Petit (2008, p. 32) insiste que "é sempre na intersubjetividade que os seres humanos se constituem, e suas trajetórias podem mudar de rumo depois de algum encontro" com a leitura. Aceitando esse pressuposto, direcionamo-nos, consequentemente, às linguagens multimídia e ao contato com a cibercultura, meio em que - devido à sua extrema multiplicidade - os variados materiais de leitura oferecem suportes, bases para que possamos, de certa forma, manusear os conteúdos da vida 
diária, aceitando-os, questionando-os e, graças ao direito à fala outorgado a todos pela conexão instantânea, contestando-os. A leitura e a interação são, assim, privilegiados instrumentos capazes de permitir o acesso às variadas formas de sociabilidade, possibilitando, inclusive, a construção da cidadania e a participação ativa em diferentes dimensões sociais.

A partir desse prisma, colaboração ativa e interação por meio dos gêneros discursivos adquirem também valor simbólico na construção da dignidade e liberdade humanas, em que o ato de ler representa uma participação efetiva no mundo, compreendendo-o e compreendendo-se como parte de um ecossistema de variadas subculturas. A prática leitora configura-se - e, nesse panorama, não haveria outra forma de concebê-la - como um processo híbrido de esforço para compreender o mundo que rodeia o sujeito e mobilização de competências semióticas variadas com a finalidade de construir sentidos. Assim, na próxima seção, discutimos as novas configurações dos gêneros discursivos, sua relação com a leitura e a construção de sentidos.

\section{GÊNEROS DISCURSIVOS: AS MÚLTIPLAS FORMAS DO DIZER}

Bakhtin (2011) já previa que os gêneros do discurso são amplamente maleáveis e adaptáveis às diversas formas de comunicação que se vinculam com as múltiplas atividades e esferas de interação humanas. Ao passo em que essas atividades, paulatinamente, modificam-se, a linguagem, a comunicação e os gêneros discursivos acompanham o mesmo movimento. Assim, se considerarmos que, devido em especial às tecnologias e às plataformas virtuais, os fazeres do homem têm se reconfigurado constantemente na contemporaneidade, é absolutamente plausível que a linguagem que representa e é refletida por esse comportamento também se remodele. É também dessas variadas esferas que surgem os enunciados, representação de gêneros e concretização de discursos, sempre únicos enquanto possibilidades de utilização da língua. Bakhtin (2011, p. 261) auxilia na construção desse conceito:

Esses enunciados refletem as condições específicas e as finalidades de cada referido campo, não só por seu conteúdo (temático) e pelo estilo da linguagem, ou seja, pela seleção dos recursos lexicais, fraseológicos e gramaticais da língua, mas, acima de tudo, por sua construção composicional.

Os reflexos da atividade humana por meio de gêneros verificam-se, então, através de seu conteúdo, estilo da linguagem e construção composicional, construindo solidamente os enunciados. Esses elementos são determinados pela especificidade de cada campo da comunicação. A magnitude e a pluralidade dos enunciados são incomensuráveis, uma vez que as relações humanas que os exigem são de possibilidades infinitas, e essa expressiva heterogeneidade torna árdua a tarefa de definir a natureza geral dos gêneros do discurso. É nesse âmbito que a língua integra a vida por meio dos enunciados e também a vida entra na língua por meio deles. Temos, assim, uma concepção sócio-histórica para a língua, enquanto fenômeno de comunicação e interação de indivíduos-sujeitos. Dessa forma, mudanças e alterações históricas na forma de comunicar têm relação direta com as mudanças dos gêneros discursivos e, somente assim, tomando o enunciado como unidade comunicativa, temos a real possibilidade de compreensão de emprego da língua enquanto sistema.

A partir dessas considerações torna-se um pouco mais clara a questão da indissolubilidade entre estilo e gênero que, por sua vez, está intimamente relacionado com os campos da atividade humana em que se dá a comunicação. As condições específicas que regem cada um desses campos (científico, publicitário, literário, político, religioso, cotidiano, de entretenimento etc.) instituem o surgimento e emprego de determinados gêneros, que correspondem a estilos específicos. Segundo Bakhtin (2011, p. 266), 
[...] o estilo é indissociável de determinadas unidades temáticas e - o que é de especial importância - de determinadas unidades composicionais: de determinados tipos de construção do conjunto, de tipos de seu acabamento, de tipos da relação do falante com outros participantes da comunicação discursiva - com os ouvintes, os leitores, os parceiros, o discurso do outro, etc. O estilo integra a unidade de gênero do enunciado como seu elemento.

Embora Bakhtin (2011) enfatize a construção composicional para a constituição do enunciado e essa é uma noção que se demonstra promissora e produtiva a pesquisadores que estudam a natureza da multimodalidade discursiva, como é nosso caso -, parece-nos também pertinente chamar a atenção para a manifestação, nos gêneros discursivos, do conteúdo (temático): trata-se, em primeira instância, do teor geral que permeia o enunciado, abarcando diferentes atribuições de sentidos e seus possíveis recortes. Se considerarmos, por exemplo, o gênero charge animada, perceberemos que a crítica social transpassa a construção panorâmica dos textos vinculados a essa esfera, e isso se aproxima da ideia de conteúdo. Já se observarmos uma ocorrência particular, em que uma charge aborde determinada crise política de uma suposta tomada ilegítima de poder, teremos nesse tópico um recorte temático, o assunto em si da construção textual ${ }^{4}$.

Conteúdo, estilo e construção composicional configuram-se, dessa forma, como elementos efetivos dos gêneros discursivos, numa relação determinada pela integração e pela solidez. É essa relação que permite uma abordagem de usos da linguagem com um prisma discursivo, garantindo o entendimento real da comunicação, consumada por meio de enunciados.

Fica claro que a ação discursiva, a partir da noção de gênero, possui fundamentos direcionais que envolvem, além dos interlocutores, a finalidade da troca comunicativa, a base temática e a elaboração composicional que, em última instância, configura em cada situação enunciativa o que é dizível, definindo, assim, a estrutura e o acabamento do gênero eleito para cada interação. Já o estilo, sendo conjunto de seleções vocabulares, lexicais e estruturais, pode se configurar como elemento de manifestação de individualidade do sujeito, embora em situações discursivas renovadas e atualizadas a cada ocorrência, sempre age diante de um sistema de restrição.

As reflexões bakhtinianas conduzem a um entendimento de enunciação como resultado da associação entre a agência nos processos de interação (linguística e social) e o sistema discursivo que torna possível essa mesma interação. É, então, nesse espaço, aberto entre sujeito, discurso e mundo, que podemos situar a linguagem concreta, entremeada axiologicamente, manifestada por meio do discurso e valendo-se do sistema da língua, em constante renovação e atualização, já que todos esses fatores estão estreitamente vinculados a uma situação histórica e social.

Tais premissas permitem-nos observar, consequentemente, a alta capacidade de adaptação dos gêneros para manifestação discursiva é reflexo da necessidade comunicativa manifestada pelos usuários da língua, que se renova paulatina e permanentemente. É nesse panorama que as inovações tecnológicas - principalmente na área da comunicação - surgem como fatores determinantes da reinvenção dos gêneros, colocando à prova a funcionalidade de antigos apoios, que se recriam para satisfazer às necessidades dos usuários e da comunicação em si.

Entretanto, as modernas tecnologias de informação e comunicação, abrindo espaço para suportes totalmente novos, permitem e sugerem o aparecimento de gêneros discursivos inéditos, com identidade própria, marcada pela relação que estabelecem com o emprego da linguagem e da língua. É o caso dos videoclipes (para já indiciarmos nossa análise posterior), viáveis graças às modernas tecnologias, e que,

\footnotetext{
${ }^{4} \mathrm{O}$ recorte temático, também classificado simplesmente como "tema" por alguns estudiosos, é visivelmente distinto do conteúdo (temático), elemento básico do enunciado.
} 
pela integração de semioses variadas como signos verbais, imagens em movimento e sons, projetam sentidos que não podem ser apreendidos se baseados nos valores individuais de cada um desses planos de comunicação.

Em relação à linguagem dos gêneros da contemporaneidade, é perceptível sua cada vez maior dinamicidade e sua predisposição à adaptação a partir de bases antigas. Diante disso, é possível que os percebamos não como formas e estruturas estagnadas e imóveis, mas como conjuntos de textos com um rol de semelhanças, e, embora fenômenos linguísticos, não são suas características linguísticas que os definem, e sim seus usos e funções como atividades sociodiscursivas e possibilidades de realização comunicativa com objetivos determinados em situações específicas.

Parece estarmos, assim, à guisa de conclusões permanentes. Uma vez que não é necessariamente a forma (linguística ou estrutural) que define os gêneros, embora isso também possa ocorrer como balizamento prévio, fica evidente que a comunicação somente se efetiva por meio deles. Também é notório que essa mesma comunicação se concretiza apenas por meio de textos. Assim, é que encontramos a verdadeira relevância do estudo dos gêneros, seja no âmbito escolar ou para a própria necessidade cotidiana de comunicar-se, já que conhecer e manusear uma gama variada de gêneros é um pressuposto que gera determinada economia linguística: por meio da interação, sabemos qual gênero está sendo utilizado e como dever acontecer essa utilização. Dessa forma, considerando sua finalidade, seus usos e funções, os gêneros permitem-se observar enquanto eventos não apenas linguísticos, mas sobretudo discursivos: estamos, sim, tratando de gêneros textuais-discursivos que, especialmente na pós-modernidade, valem-se da noção de multiplicidade, tópico explorado na próxima seção.

\subsection{CULTURAS, SEMIOSES E PLATAFORMAS: A VEZ DO MULTI}

Vinculando-nos diretamente ao panorama descrito até então, percebemos que os textos de gêneros multimodais oferecem o atrativo das semioses variadas projetadas de modo simultâneo, uma das faces da multiplicidade, conceito que ancora este estudo. Preliminarmente, vale salientar que, se por meio de textos, imagens e sons, simbolicamente é possível castigar, condenar, punir, é também possível proteger, resguardar, asilar, ou, como prefere Kress (2000), ações sociais são fenômenos multimodais. Mais fortemente ainda acontece a influência desses sistemas nos processos de interação por meio da comunicação quando estiverem integrados: palavras, imagens e sons associados na projeção de sentidos operam conjunta e simultaneamente com a finalidade de discursivizar. Indissociável do conceito de multimodalidade está a noção de multiletramento: "capacidade de colocar-se em relação às diversas modalidades de linguagens - oral, escrita, imagem, imagem em movimento, gráficos, infográficos etc. - para delas tirar sentido" (ROJO, 2012, p. 31). O cenário contemporâneo estimula a multimodalização de gêneros, e é a popularização de suas variedades multimodais que torna o momento propício à sugestão de novos instrumentos possibilitadores da construção de sentidos, em que o hibridismo seja entendido como a combinação das significâncias empregadas de forma sincrônica.

Em potencial participação ativa em processos de mudança social, os multiletramentos estão relacionados com representações mais amplas que as linguagens multissemióticas, consideram elementos culturais e sociais específicos, além dos variados modos de significação por meio dos quais os sujeitos interagem para atingir seus propósitos comunicativos (COPE; KALANTZIS, 2000).

Desse modo, tornam-se essenciais novas concepções para interação com textos de gêneros multimodais e configura-se como uma exigência que novos letramentos sejam desenvolvidos - tarefa ainda atribuída exclusivamente à escola. Essa perspectiva pressupõe a renovação das aulas de língua materna, em que se lance mão da aplicação de novos paradigmas de ensino e de aprendizagem, como é 
o caso de uma "pedagogia dos multiletramentos". Rojo (2012), apoiada nas contribuições do "Grupo Nova Londres", apresenta uma sistematização dessa dinâmica, em que o ensino e a aprendizagem teriam base em prática situada, instrução aberta, enquadramento crítico e prática transformadora. É indispensável que a prática de uma pedagogia dessa natureza enfatize o que de fato a torna múltipla: "a multiculturalidade característica das sociedades globalizadas e a multimodalidade dos textos por meio dos quais a multiculturalidade se comunica e informa" (ROJO, 2012, p. 13). É assim que a experiência singular e íntima da leitura crítica e autônoma converte-se em princípio estrutural da prática do multiletramento ${ }^{5}$. E para o concreto desenvolvimento de competências linguístico-discursivas, é indispensável que o referido hibridismo seja percebido "como a combinação das significâncias empregadas de forma sincrônica. Desse modo, tornam-se essenciais novas concepções para interação com textos de gêneros multimodais e configura-se como uma exigência que novos letramentos sejam desenvolvidos" (OLDONI; DE FREITAS, 2015, p. 185).

Isso posto, destacamos, a partir das palavras de Rojo (2012, p. 23), as características fundamentais dos multiletramentos:

(a) eles são interativos; mais que isso, colaborativos;

(b) eles fraturam e transgridem as relações de poder estabelecidas, em especial as relações de propriedade (das máquinas, das ferramentas, das ideias, dos textos [verbais ou não]);

(c) eles são híbridos, fronteiriços, mestiços (de linguagens, modos, mídias e culturas).

Em relação ao caráter interativo dos multiletramentos, vale ressaltar que, devido à sua relação intrínseca com a multimodalidade discursiva, essa interatividade acontece em patamares diversos, principalmente por meio das multimídias - conforme expusemos anteriormente - e, por isso, depende de nossas provocações e de nossa agência enquanto sujeitos-usuários. Essa interatividade transforma-se rapidamente em colaboração e interação, já que o uso das plataformas virtuais e as mídias digitais têm como princípio fundante a interação/convívio dos usuários, que somente se concretiza em ações cooperativas.

Ocorre que, por conta dessa mudança significativa relacionada ao manuseio das plataformas de comunicação, e considerando a vinculação com os meios digitais pela maioria dos estudantes com os quais trabalhamos, as intervenções didático-pedagógicas devem, então, estar voltadas para uma aprendizagem também interativa e flexível, e não puramente curricular, com conteúdos e métodos engessados e pré-definidos.

Recorrendo a Rojo (2012, p. 27) mais uma vez, "vivemos em um mundo em que se espera [...] que as pessoas saibam guiar suas próprias aprendizagens na direção do possível, do necessário e do desejável, que tenham autonomia e saibam buscar como e o que aprender, [...] e consigam colaborar com a urbanidade". Os métodos de trabalho escolares e a educação linguística que privilegiem os multiletramentos devem apresentar, pois, condições para que, amparados nas múltiplas possibilidades discursivas, os estudantes possam construir e consolidar os sentidos projetados/pretendidos pelo entorno linguístico multimodal e lidar com eficiência com seus processos de produção, visto que é deles exigido que cada vez mais refinem e aperfeiçoem suas habilidades de leitura e escrita. Por meio do desenvolvimento de competências que permitam ao sujeito a apreensão da diversidade cultural e

\footnotetext{
${ }^{5}$ Considerando esse panorama é que proporemos, na próxima seção, a vinculação de tópicos semantizadores à análise de gêneros multimodais, para identificar elementos indispensáveis à sua interpretação e à construção real de sentidos, como forma de apontar caminhos para uma produção de conhecimentos cada vez mais expressiva e contribuir de forma efetiva para o multiletramento.
} 
linguística, constroem-se também novas noções de cidadania; justapondo diferentes linguagens, discursos, estilos, abordagens e semioses, amplia-se, por meio da mesma dinâmica, a capacidade de pensar criticamente sistemas complexos e suas interações (THE NEW LONDON GROUP, 2000). Tal hibridismo é o que, na materialidade discursiva, enfocamos na sequência.

\section{O GÊNERO VIDEOCLIPE E A CONSTRUÇÃO DO SENTIDO NA MULTIMODALIDADE}

Para operacionalização do cenário teórico exposto anteriormente, adotamos como metodologia deste estudo a identificação de seus tópicos semantizadores ${ }^{6}$ (OLDONI, 2015) na reconstrução exploratória do sentido do gênero multimodal que nos serve de corpus, o videoclipe de abertura da série de comédia dramática Orange Is The New Black ${ }^{7}$. Elementos indispensáveis à leitura da materialidade discursiva e à construção real de sentidos dos mais variados gêneros, os tópicos semantizadores funcionam como roteirizadores da semantização, em que alguns itens se tornam pontos aglutinadores de sentidos a serem resgatados. A partir de tal procedimento, no âmbito da genericidade, consideramos fatores como esfera de comunicação, valor social, conteúdo (temático), forma composicional, estilo e multiplicidade cultural e semiótica como pressupostos e colaboradores do engendramento e harmonização dos planos visual, imagético e sonoro e, nessa dinâmica, resgatamos os pontos nodais da construção do sentido na materialidade em questão.

Reproduzimos, por meio da Figura 1, uma captura de tela representativa de um quadro do videoclipe, como forma de elucidação ${ }^{8}$.

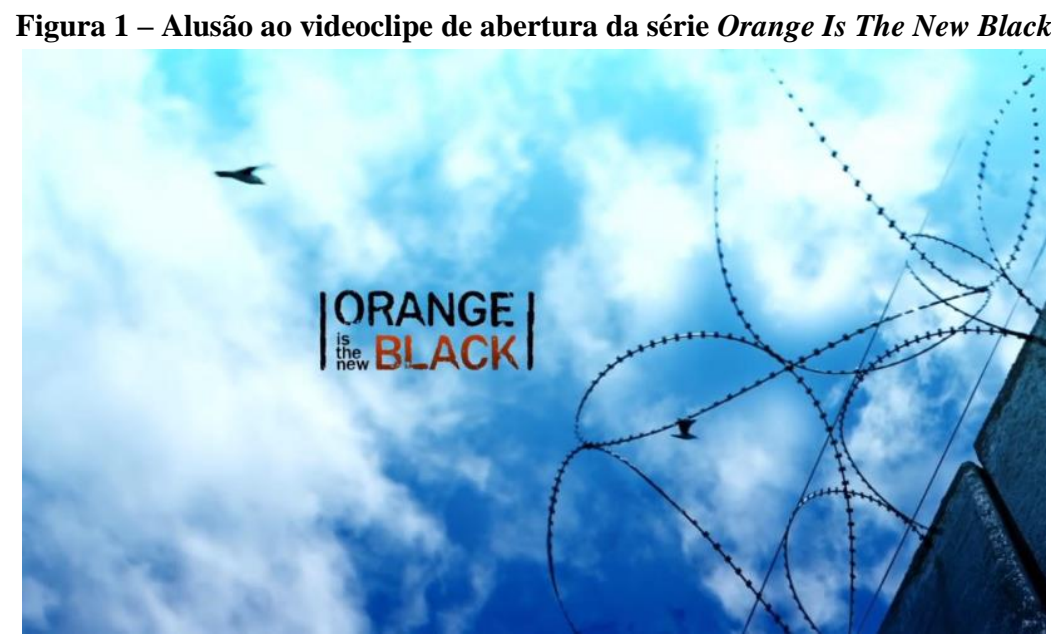

Fonte: YouTube (2017)

A dinâmica de resgate de sentidos projetados por um texto multimodal só é possível por meio da leitura da globalidade dos signos que o compõem. A partir dessa premissa - embora saibamos das controvérsias que acompanham as discussões acerca de um suposto conceito único de leitura - aceitamos que, além de sentidos, compreendidos, analisados e percebidos, palavras, imagens e sons podem também ser lidos. E essa leitura implica, necessariamente, interação. Conforme é perceptível, cada vez mais a ideia de multiplicidade mostra-se atual e pertinente. Além de estar presente quando nos referimos a

\footnotetext{
${ }^{6}$ A noção de "tópico semantizador" foi por nós explorada em trabalho anterior, intitulado "Textos e imagens em cena: o sentido nos gêneros multimodais", e demonstra-se, conforme entendemos, suficientemente produtiva para a análise aqui empreendida. ${ }^{7}$ A escolha do corpus justifica-se pela significativa abrangência das séries dessa natureza, conquistando um grande público mundialmente; à parte isso, consideramos que esse público expectador converte-se também em leitor dos seus videoclipes de abertura que merecem, então, um estudo mais específico para compreensão da projeção de seus sentidos.

${ }^{8}$ Consideramos apenas uma alusão, posto que os sentidos do corpus, texto de gênero multimodal, não podem ser resgatados por meio de uma imagem, apenas.
} 
fontes, fragmentos, culturas e plataformas, também está relacionada com a pluralidade do universo de signos que dão sua parcela de contribuição à linguagem multimodal.

Assim, a partir dos pressupostos metodológicos que propusemos no início desta seção, é conveniente que iniciemos a exploração do videoclipe aqui enfocado abordando sua esfera de comunicação. A série de comédia dramática americana Orange Is The New Black é produzida e veiculada pela plataforma Netflix, provedora global de filmes e séries, com mais de 90 milhões de assinantes, presente em cerca de 190 países, atualmente. Dessa maneira, os expectadores da série, leitores de seu videoclipe de abertura (nosso corpus), configuram-se como um público específico e selecionado, possivelmente interessados em tal leitura relacionada ao domínio do /Entretenimento/ ${ }^{9}$. É esse o tópico semantizador a que aludimos na reconstrução e no resgaste do sentido do gênero discursivo, em referência à sua esfera de atividade e comunicação humana.

Em íntima relação com tal esfera, estão os aspectos axiológicos legíveis do gênero. O leitor do videoclipe atribui determinados valores sociais ao encontro com a leitura, como descreveria Petit (2008). Como essa valoração não se dá simplesmente a partir do lugar social, mas na interação com o discurso por meio do gênero, consideramos plausível que o resgate de seus tópicos aconteça em comunhão com a exploração dos elementos centrais do enunciado: conteúdo (temático), construção composicional e estilo, por sua vez, indissociáveis, segundo Bakhtin (2011).

Os engendramentos semióticos - envolvendo texto verbal, sons e imagens estáticas e em movimento - viabilizadores da multimodalidade discursiva são constituintes naturais dos elementos centrais do gênero e não concebemos seu isolamento para análise, embora algumas significações possam ser resgatadas especificamente conforme veremos ainda nesta seção.

Preliminarmente, é necessário que atentemos para a premissa de que, no resgate do sentido global do gênero em análise, alguns aspectos oferecem atrativos bastante pontuais: é o caso da /Sincronia/ entre a cadência ${ }^{10}$ da música (ou canção) e a apresentação de imagens fotográficas com partes de rostos femininos, em que o /Ritmo/ associa-se intimamente com a troca de quadros. Estes tópicos remetem, invariavelmente à letra da música, que alude, em determinado trecho, ao /Aconselhamento/ "Lembre-se de todos os seus rostos" 11 que gera, a partir do instauração de um "tu" interlocutor e do emprego do pronome "seus", um /Convite/ ao /Reconhecimento/ do próprio leitor como possível integrante dos quadros apresentados. Como resultado dessa dinâmica, a /Alteridade/ também pode ser considerada semantizadora do gênero, tanto em relação às trocas de imagens de supostas personagens da série, quanto em alusão à integração do leitor aos quadros.

Ainda em relação à exposição dos rostos, ou partes deles, vale ressaltar a ideia de /Diversidade/, representada pelas idades, etnias, expressões faciais e acessórios variados, o que entra em confronto com a /Suposta Uniformidade/ sugerida pela pelas roupas (uniformes), gerando um interessante jogo de sentidos. Da mesma maneira, os trajes padronizados que, em tese, gerariam a sensação de regularidade e disciplina, refletem apenas um /Simulado Apagamento da Subjetividade/ que, efetivamente, ganha contornos nítidos por meio das marcas individuais que se sobressaem.

São, ainda, essas mesmas marcas de /Individualidade/, que suscitam semantizações como /Histórias de Vida/, /Ponto de Vista/, /Expectativa/, /Esperança/, em dicotomia com /Frieza/, /Sofrimento/, /Preocupação/, /Tristeza/. Se, por um lado, evidenciamos esses pontos na materialidade, a partir da harmonização dos planos de sentido envolvidos na composição do videoclipe, por outro lado,

\footnotetext{
${ }^{9}$ Entre barras, destacamos os "tópicos semantizadores", pontos centrais da construção de sentidos.

${ }^{10}$ Neste estudo não utilizaremos termos específicos da área da música, posto que tais nomenclaturas, em última instância, não interferem na construção dos sentidos.

${ }^{11}$ Neste estudo, estamos adotando processo de tradução livre, já que a canção, no gênero em análise, é veiculada em língua inglesa.
} 
é indispensável percebermos, nesse mesmo fluxo, que é somente a partir de um valor ideológico que se pode identificar, por exemplo, a /Esperança/ como nó de sentido, é algo que se aproxima de uma construção colaborativa e coletiva a noção de que o /Encarceramento/ representa, simbólica e moralmente, a crença do recomeço e a fé nas melhorias pessoais e sociais.

Quanto a esse último tópico que enfatizamos, percebemos sua associação direta a partir de todas as semioses envolvidas na concretização do gênero: imagens de celas, som de grades se fechando e alusão verbal direta a presos e gaiola. No entanto, o sentido a ser resgatado não se encontra em tais semioses, individualmente: a imagem, o som ou a palavra, por si, não reconstroem a noção dinâmica projetada por sua associação. É a justaposição de linguagens e semioses que possibilita o potencial de reflexão acerca desse mesmo processo de interação (THE NEW LONDON GROUP, 2000).

É importante, neste ponto, que insistamos na ideia da multissemiose, tão enfatizada por Rojo (2012). Valendo-nos do tópico semantizador /Esperança/, há pouco indiciado, percebemos que seu emergência a partir da concretude genérica acontece não somente por alusões diretas de planos variados - como a letra da canção, em especial o trecho "Todo mundo está esperando por você / E você tem tempo"; ou pela ênfase dada ao céu e aos pássaros em movimento para o exterior dos muros, no plano imagético; tampouco devido ao arranjo sugestivamente animado e expansivo da música -, mas pela comunhão de suas significações, quando observadas, sentidas, percebidas, lidas em colaboração mútua.

Assim, valendo-se desse mesmo princípio e em função do engendramento das semioses permeado pela valoração social e ideológica, ainda temos /Controle/, /Limitação/, /Privação de Liberdade/, /(In)Justiça/, /Punição/, /Conflito/, /Adaptação/, /Privilégio/, /Isolamento/, /Distanciamento/, /Escolhas/, /Possibilidades/, /Oportunidades/ como tópicos semantizadores do videoclipe de abertura da série Orange Is The New Black.

\subsection{NO MULTILETRAMENTO, O RESGATE DA MULTIPLICIDADE}

A leitura de textos de gêneros multimodais, como um videoclipe, implica a mobilização de sofisticados recursos para o efetivo resgate dos sentidos projetados, conforme estamos demonstrando por meio desta análise e já havíamos afirmado em pesquisa anterior: "nos meios intersemióticos, cada sistema se constrói a partir de seus próprios signos, mas em função simultânea às projeções e valores dos signos de um plano adicional, ao qual o primeiro está vinculado" (OLDONI; DE FREITAS, 2015, p. 186). Entretanto, ressaltamos que nossas proposições revelam apenas uma possibilidade de semantização do gênero em questão. Cada leitor, a partir de seu encontro com a leitura, reconstrói, a seu modo e de acordo com seus valores, os possíveis sentidos da materialidade do gênero.

As contribuições de Cope e Kalantzis (2000), Rojo (2012) e, de maneira geral, do Grupo Nova Londres (2000), conforme discutimos anteriormente, oferecem-nos importantes subsídios para considerarmos que, em última instância, é a partir da noção de multiplicidade que os sentidos da multimodalidade discursiva podem ser resgatados. Nesse aspecto é que o multiletramento torna-se processo e pressuposto. A multiculturalidade refletida no videoclipe, em que um tema - como preferiria Bakhtin (2011) - periférico e marginalizado (a vida no cárcere) torna-se presente e popular aos olhos do leitor, contribui também para o surgimento da /Realidade/ como semantizador do gênero.

Da mesma maneira, as multissemioses - como efetivação de uma forma composicional, premissas de um estilo próprio do gênero e viabilizadoras da discursivização de um conteúdo - em sua natureza geram algumas semantizações. O videoclipe aqui em análise promove, nesse âmbito, sugere tópicos semantizadores como /Movimento/, /Tendência/, /Reflexão/, /Intencionalidade/, /Atratividade/, /Divulgação/, /Ambientação/ e /Roteirização/, que precisam ser resgatados pelo leitor do gênero para 
construção de sentidos mais específicos. É, para citar apenas um exemplo, a partir da /Roteirização/ que os sentidos vinculados à /Diversidade/ podem ser construídos.

Estamos cientes de que as considerações aqui expostas representam apenas uma dentre as produtivas possibilidades de construção de sentidos da multimodalidade discursiva: resgatar os pontos principais da semantização de gêneros requer a observação atenta e a leitura colaborativa, em uma efetiva dinâmica de troca e interação. Assim, como forma de sistematização, apresentamos o Quadro 1, que aglutina os pontos nevrálgicos do resgate de sentidos do corpus e permite sua apreensão global.

Quadro 1 - Tópicos semantizadores do videoclipe de abertura da série Orange Is The New Black

\begin{tabular}{|c|c|c|}
\hline Critérios metodológicos empregados & \multicolumn{2}{|c|}{ Tópicos Semantizadores } \\
\hline & /Entretenimento/ & /Controle/ \\
& /Sincronia/ & /Limitação/ \\
& /Ritmo/ & /Privação de liberdade/ \\
& /Aconselhamento/ & /In)Justiça/ \\
& /Convite/ & /Punição/ \\
Esfera de comunicação & /Reconhecimento/ & /Conflito/ \\
Valor social & /Alteridade/ & /Adaptação/ \\
& /Diversidade/ & /Privilégio/ \\
Conteúdo (temático) & /Isolamento/ \\
Forma composicional & /Suposta Uniformidade/ & /Distanciamento/ \\
Estilo & /Simulado Apagamento da & /Possibilidades/ \\
& Subjetividade/ & /Oportunidades/ \\
Multiplicidade cultural & /Individualidade/ & /Movimento/ \\
Multiplicidade semiótica & /Histórias de Vida/ & /Tendência/ \\
& /Ponto de Vista/ & /Reflexão/ \\
& /Expectativa/ & /Intencionalidade/ \\
& /Esperança/ & /Atratividade/ \\
& /Frieza/ & /Divulgação/ \\
& /Sofrimento/ & /Ambientação/ \\
& /Preocupação/ & /Roteirização/ \\
\hline
\end{tabular}

Fonte: Elaborado pelos autores

A competência discursiva que permite a mobilização de suficientes recursos para resgate dos tópicos recém-citados perpassa, obrigatoriamente, uma nova configuração de leitor. A vida, a realidade, a linguagem, os discursos são múltiplos, e o leitor intensa e permanentemente envolvido em processos discursivos também deve ser. Justamente a partir disso surge o que pode se considerar uma característica do sujeito que lê na contemporaneidade, a atenção contínua à multiplicidade. É esse traço de seu perfil - cremos que o principal traço - que habilita o leitor a mover-se pelos ambientes físicos urbanos lendo sinais e signos diversos e, ao mesmo tempo, sem necessidade de pausa, imergir no ciberespaço para acessar qualquer universo informacional, conectar-se às redes sociais ou realizar uma lista sem fim de possíveis atividades.

Assim como os estímulos da multiplicidade cultural e semiótica, também múltiplas são as capacidades discursivas de processamento simultâneo da mensagens, informações e sinais com que temos contato: acontecem, a todo instante, as integrações multissemiótica e multicultural mediadas e refletidas nos discursos da contemporaneidade. E já que as reações a esses estímulos verbais, sonoros, imagéticos, semióticos, enfim, são imediatas, não há outra possibilidade a não ser considerarmos que a atenção é contínua e o envolvimento íntimo com as multissemioses é necessário.

No entanto, se por um lado são merecidamente louváveis as capacidades advindas de um estado ininterrupto de alerta à discursividade múltipla, que exige atenção permanente, por outro lado torna-se 
absolutamente desassossegadora a constatação de quem nem todos os leitores estão aptos a participar dessa dinâmica. E para o desassossego transformar-se em empecilho para as práticas discursivas efetivas que se dão por meio da leitura, basta que o sujeito não esteja habilitado a seguir o multifluxo. Consequentemente, se o universo sígnico é múltiplo, os leitores também precisam sê-lo.

Conforme foi possível perceber por meio do panorama esboçado até então, estamos tratando de uma nova tecnologia da comunicação, não apenas no sentido clássico atribuído a ela, mas uma tecnologia enquanto mobilização de um conjunto de ações, práticas e habilidades com a finalidade específica de manusear novos objetos: os gêneros discursivos multimodais ambientados em plataformas também digitais, como o videoclipe de abertura da série Orange Is The New Black.

\section{ALGUMAS CONSIDERAÇÕES FINAIS (E TEMPORÁRIAS)}

Parece-nos justo e plausível reconhecer que as faces contemporâneas do real exigem uma leitura global para a percepção das representações simbólicas de cultura, em que os usos intersemióticos da linguagem permitem que a própria vida e sua multiplicidade sejam semantizadas por meio dos gêneros discursivos multimodais.

Os desafios trazidos pela comunicação multimodal contemporânea para as práticas sociais e discursivas estão apenas começando a ser percebidos ao passo em que se torna concreta a fusão entre culturas e semioses, espaço em que a leitura firma-se como a prática de uma verdadeira subjetividade compartilhada. É com esse balizamento referencial que, para o leitor, torna-se compulsório ler a multiplicidade, organizar eficazes planos de leitura nas também múltiplas plataformas, mobilizar tecnologias pessoais para perceber, interagir e integrar-se aos multi, reconhecer os variados fragmentos de realidade postos em conexão, letrar-se novamente.

Estas considerações finais são também temporárias - e possivelmente sempre serão! -, pois algumas questões relacionadas às reflexões empreendidas continuam à espera de respostas que cabem também ao sujeito que lê, atualiza e concretiza o universo multimodal, interage por meio de novos gêneros e dá sua parcela de contribuição às manifestações multiculturais. Esse leitor liberto, com autonomia, possibilidade ampla de avaliação - aprovação ou rejeição - daquilo que constrói com sua prática leitora, avaliza, mais do que em qualquer tempo, que leitura é encontro, leitura é descoberta, leitura é experiência de reconstrução do mundo.

Se, por muito tempo, a leitura foi concebida como mero instrumento de decodificação, as experiências humanas comprovaram que os princípios de liberdade, criticidade e emancipação também podem ser conquistados por meio do ato de ler. É esse mesmo ato que, na contemporaneidade, amplia profundamente seu sentido. Hoje, a dinâmica da leitura representa - sem receio da hipérbole - um arauto de novo mundo: se, por um lado, a leitura dá acesso às representações simbólicas da realidade em sua multiplicidade, por outro lado, essa realidade somente se constrói por meio da própria leitura.

\section{REFERÊNCIAS}

BAKHTIN, Mikhail. Os gêneros do discurso. In: Estética da criação verbal. São Paulo: Martins Fontes, 2011. p. 277-326.

COPE, B.; KALANTZIS, M. Introduction: the beginnings of an idea. In: Multiliteracies: literacy learning and the design of social futures. London: Routledge, 2000. p. 03-08.

KRESS, Gunther. Multimodality. In: COPE, B.; KALANTZIS, M. Multiliteracies: literacy learning and the design of social futures. London: Routledge, 2000. p. 182-202. 
OLDONI, Cristiano. Textos e imagens em cena: o sentido nos gêneros multimodais. 2015.

Dissertação (Mestrado em Letras) - Instituto de Filosofia e Ciências Humanas, Universidade de Passo Fundo, Passo Fundo, 2015.

OLDONI, Cristiano; DE FREITAS, Ernani Cesar. Textos e imagens em cena: o sentido nos gêneros multimodais. Todas as Letras - Revista de Língua e Literatura, Universidade Mackenzie (SP), v. 17, n. 3, p. 182-195, 2015. Disponível em:

<http://editorarevistas.mackenzie.br/index.php/tl/article/view/7846/5620>. Acesso em: 18 maio 2017.

ORANGE IS THE NEW BLACK - Abertura. Disponível em:

<https://www.youtube.com/watch?v=fBITGyJynfA>. Acesso em: 18 maio 2017.

PETIT, Michèle. Os jovens e a leitura: uma nova perspectiva. São Paulo: Editora 34, 2008.

ROJO, Roxane. Pedagogia dos multiletramentos: diversidade cultural e de linguagens na escola. In: ROJO, Roxane; MOURA, Eduardo (Orgs.). Multiletramentos na escola. São Paulo: Parábola Editorial, 2012. p. 11-31.

THE NEW LONDON GROUP. A pedagogy os Multiliteracies: designing social futures. In: COPE, B.; KALANTZIS, M. Multiliteracies: literacy learning and the design of social futures. London: Routledge, 2000. p. 09-37. 